\title{
Rhinovirus Upper Respiratory Infection Increases Airway Hyperreactivity and Late Asthmatic Reactions
}

\author{
Robert F. Lemanske, Jr., Elliot C. Dick, Cheri A. Swenson, Rose F. Vrtis, and William W. Busse \\ University of Wisconsin Medical School, Departments of Medicine, Pediatrics, and Preventive Medicine, Madison, Wisconsin 53792
}

\begin{abstract}
Although viral upper respiratory infections (URIs) provoke wheezing in many asthma patients, the effect of these illnesses on the airway response to inhaled antigen is not established. The following study evaluated the effect of an experimental rhinovirus (RV) illness on airway reactivity and response to antigen in 10 adult ragweed allergic rhinitis patients. Preinfection studies included measurements of airway reactivity to histamine and ragweed antigen. Furthermore, the patients were also evaluated for late asthmatic reactions (LARs) to antigen (a 15\% decrease in forced expiratory volume of the first second $\sim 6 \mathrm{~h}$ after antigen challenge). $1 \mathrm{mo}$ after baseline studies, the patients were intranasally inoculated with live RV16. All 10 patients were infected as evidenced by rhinovirus recovery in nasal washings and respiratory symptoms. Baseline FEV values were stable throughout the study. During the acute RV illness, there was a significant increase in airway reactivity to both histamine and ragweed antigen $(P=0.019$ and 0.014 , respectively). Before $R V$ inoculation, only 1 of the 10 subjects had an LAR after antigen challenge. However, during the acute RV illness, 8 of 10 patients had an LAR $(P<0.0085$ compared with baseline); the development of LARs was independent of changes in airway reactivity and the intensity of the immediate response to antigen. Therefore, we found that not only does a $R V$ respiratory tract illness enhance airway reactivity, but it also predisposes the allergic patient to develop LARs, which may be an important factor in virus-induced bronchial hyperresponsiveness.
\end{abstract}

\section{Introduction}

Upper respiratory infections (URIs) ${ }^{1}$ trigger wheezing in many asthma patients (1-4). Epidemiological studies have demonstrated that viral, not bacterial, respiratory infections precipi-

Address reprint requests to Robert F. Lemanske, Jr., Clinical Science Center, University of Wisconsin, 600 Highland Avenue, H6 367, Madison, WI 53792.

Received for publication 27 January 1988 and in revised form 19 July 1988.

1. Abbreviations used in this paper: $\mathrm{FEF}_{25-75 \%}$, forced midexpiratory flow rate; $\mathrm{FEV}_{1}$, forced expiratory volume of the first second; FVC, forced vital capacity; $\mathrm{HR}$, histamine release; LAR, late asthmatic reaction; $\mathrm{PD}_{20}, 20 \%$ provocative dose; Pipes, piperazine- $N, N^{\prime}$-bis(2-ethanesulfonic acid); Pipes-CM, Pipes plus $1 \mathrm{mM} \mathrm{Ca}^{2+}$ and $1 \mathrm{mM} \mathrm{Mg}^{2+}$; $\mathrm{RV}$, rhinovirus; $\mathrm{TCID}_{50}, 50 \%$ tissue culture infective dose; URI, upper respiratory infection.

J. Clin. Invest.

(C) The American Society for Clinical Investigation, Inc. $0021-9738 / 89 / 01 / 0001 / 10 \quad \$ 2.00$

Volume 83, January 1989, 1-10 tate these asthma attacks. Furthermore, the respiratory virus identified with increased asthma is largely determined by the age of the patient. Wheezing in infants and young children is most commonly associated with respiratory syncytial virus infections, whereas older asthma patients have similar exacerbations, but in this age group, rhinovirus (RV) infections are often precipitants (3). Although the infectious etiology of these wheezing episodes has been determined, mechanisms to explain asthma attacks with respiratory infections remain to be established (5).

A number of mechanisms have been proposed to explain virus-induced asthma, including airway injury by the infectious pathogen $(6,7)$, diminished beta adrenergic function (8-11), production of virus-specific IgE-antibodies (12-14), and enhanced leukocyte histamine release $(15,16)$. High titers of IgE-antibodies to respiratory syncytial virus and parainfluenza virus are found in children with asthma-like illnesses; these individuals are more prone to recurrent episodes of wheezing (12-14). The precise role of virus-specific IgE antibodies to the pathogenesis of airway hyperreactivity, or asthma, has yet to be clarified. Nonetheless, the potential contribution of immediate hypersensitivity reactions to virus-induced wheezing is highly likely as products of the pulmonary mast cell can be linked to acute bronchospasm, persistent bronchial inflammation, and increased airway reactivity as illustrated by the development of late asthmatic reactions (LARs) (17).

This study examined the effects that an $R V$ respiratory infection has on airway reactivity and the pattern of pulmonary response that develops after aerosolized antigen challenge.

\section{Methods}

Patient selection. 10 patients were selected for study. There were eight males and two females with an average of $30.6 \pm 2.2($ mean $+S E)$ yr. All patients had a positive immediate skin test reaction by the prick method to an extract of ragweed antigen $(1 / 20 \mathrm{wt} / \mathrm{vol}$, Greer Laboratories, Lenoir, NC), released leukocyte histamine after an in vitro incubation with ragweed antigen $\mathrm{E}$, and lacked neutralizing antibody in their sera to rhinovirus 16 (RV16). None of the patients smoked, had active clinical asthma, or used any medication at the time of study. All patients gave informed consent before enrolling in the study, which was conducted during periods when the patients were free of allergic rhinitis symptoms.

For a number of reasons, we first chose to evaluate the effects of an $\mathrm{RV}$ illness in allergic rhinitis subjects rather than asthma patients. First, although patients with allergic rhinitis do not have clinical asthma, their airway responsiveness is often enhanced when compared with normal patients (18). Second, in patients with allergic rhinitis, it would be unlikely to find abnormal airway smooth muscle with characteristics similar to those noted in asthma (e.g., hypertrophy, hyperreactivity, or inflammation) to complicate the effects that a respiratory illness may have on pulmonary function. Third, none of the patients required bronchodilator medication that could interfere with the in- 
terpretation of changes in airway function. Finally, we were concerned that an acute airway infection could provoke an attack of wheezing in patients with underlying asthma.

Study design. The patients were studied on three separate occasions, each $28 \mathrm{~d}$ apart, as indicated by the schematic protocol in Fig. 1: baseline, acute URI, and recovery. At each study period, the patients were evaluated on three consecutive days. Evaluations consisted of first, spirometry (forced expiratory volume of the first second [FEV $\left.V_{1}\right]$, forced vital capacity [FVC], and forced midexpiratory flow rate $\left[\mathrm{FEF}_{25-75 \%]}\right]$, which was performed before initiating bronchoprovocation studies; second, airway reactivity, which was measured by bronchoprovocation on separate days to aerosols of histamine (preantigen), ragweed antigen, and histamine again (postantigen); and third, leukocyte histamine release, which was measured at each of the three study occasions before any bronchoprovocation.

Reagents. Pipes (piperazine- $N, N^{\prime}$-bis [2-ethanesulfonic acid]) was purchased from Sigma Chemical Co. (St. Louis, MO). The calcium ionophore A23187 was bought from Calbiochem-Behring Corp. (Los Angeles, CA). Ragweed antigen E was obtained from the Research Resource Branch of the National Institutes of Health (Bethesda, MD). Con A was purchased from Miles Research Products Division (Elkhart, IN). Aqueous extracts of ragweed for bronchoprovocation were obtained from Greer Laboratories.

Leukocyte separation procedure. Blood was obtained by venipuncture and anticoagulated with EDTA, $0.5 \mathrm{ml} 2.7 \%$ EDTA per $9.5 \mathrm{ml}$ of blood, before separation by density gradient centrifugation on FicollHypaque cushions (19). The mononuclear cell band containing basophils was removed, washed three times with Pipes-CM $\left(1 \mathrm{mM} \mathrm{Ca}^{2+}\right.$ and $1 \mathrm{mM} \mathrm{Mg}^{2+} \mathrm{pH}$ 7.4) and then suspended in Pipes-CM. PMNs were then isolated after dextran sedimentation and hypotonic lysis of con- taminating erythrocytes before suspension in HBSS. Cell viability for all experiments was indicated by $>95 \%$ exclusion of trypan blue dye.

Measurement of leukocyte histamine release. Isolated leukocyte suspensions $\left(2-4 \times 10^{6}\right.$ cells $\left./ \mathrm{ml}\right)$ containing basophils were added to 10 $\times 75 \mathrm{~mm}$ plastic tubes (Falcon Labware, Oxnard, CA) in $0.5-\mathrm{ml}$ replicate samples. After temperature equilibration $\left(37^{\circ} \mathrm{C}\right.$ for $\left.10 \mathrm{~min}\right)$, ragweed antigen $\mathrm{E}$, freshly prepared Con $\mathrm{A}$, or the calcium ionophore A23187 was added to the leukocyte suspensions. After a 30-min incubation, the reaction was terminated by immersion of the leukocytecontaining test tubes into an ice-water bath for $10 \mathrm{~min}$ followed by rapid centrifugation for 1.5 min (Serofuge; Clay Adams Div., BectonDickinson \& Co., Parsippany, NJ). The supernatants were removed for measurement of histamine. Total leukocyte histamine was determined after cell suspension in $3 \%$ perchloric acid.

Histamine analyses were performed by an automated fluorometric technique that uses the organic extraction of histamine and its linkage to $o$-phthalaldehyde $(20,21)$. The percent histamine release (HR) was calculated by the following formula: $\% \mathrm{HR}=100 \times($ experimental supernatant HR-blank/total leukocyte histamine-blank). The blank, or spontaneous histamine release, never exceeded $6 \%$ of the total histamine when performed in calcium-containing buffer. This method is sensitive to $5.0 \mathrm{ng} / \mathrm{ml}$ of histamine.

Bronchial provocation tests. Airway reactivity to histamine and ragweed antigen was determined in the 10 patients by standard bronchial provocation techniques to increasing concentrations of either histamine or ragweed antigen aerosol delivered through a nebulizer (DeVilbiss Co., Somerset, PA) attached to a French-Rosenthal dosimeter (22). Bronchial provocation was performed by having the patient inhale from functional residual capacity to vital capacity with a 10 -s breath hold. Histamine concentrations $(0.03,0.06,0.12,0.25,0.5$,

Schematic Experimental Design for RV 16 Infection

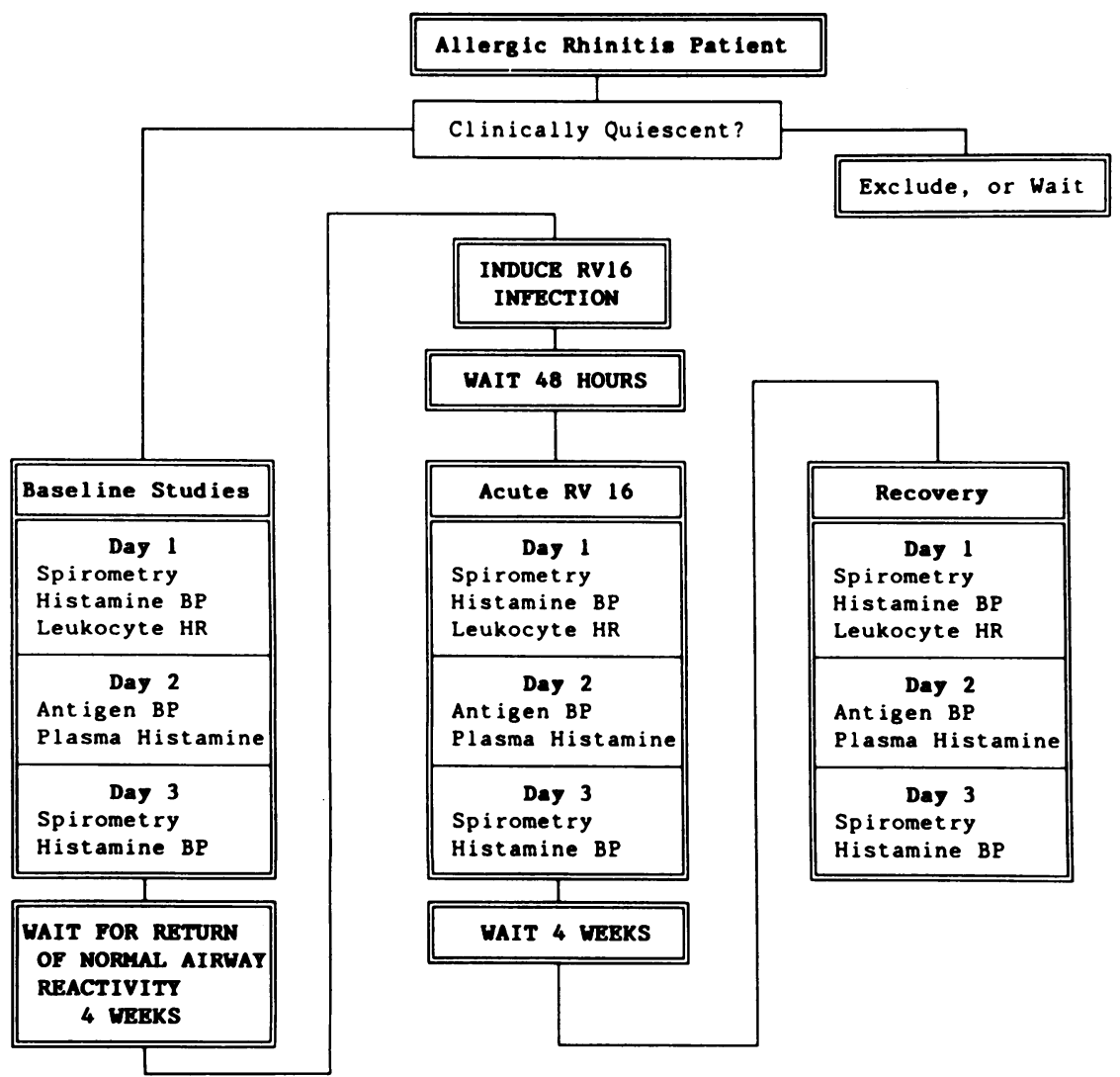

Figure 1. Schematic experimental design for RV16 inoculation. BP, bronchoprovocation; HR, histamine release. 
$1.0,2.0,5.0,10.0$, and $25.0 \mathrm{mg} / \mathrm{ml}$ ) were prepared from a stock solution and diluted in buffered saline (pH 7.4). Similarly, extracts of ragweed antigen in increasing concentrations $(0.5,1.0,5.0,10.0,50.0$, $100.0,500.0$, or $1,000.0$ protein nitrogen units $(\mathrm{PNU}) / \mathrm{ml})$ were prepared from a stock solution $(20,000 \mathrm{PNU} / \mathrm{ml})$ and diluted in buffered saline (pH 7.4).

If an initial aerosol of buffered saline did not significantly change the baseline $\mathrm{FEV}_{1}$, increasing concentrations of histamine were given at 5-min intervals until the $\mathrm{FEV}_{1}$ fell at least $20 \%$ from the baseline measurement and was sustained at this level for $5 \mathrm{~min}$. Spirometry was performed on a spirometer (Cardio-Pulmonary Instruments, Houston, TX), with the best of three efforts for the FEV , being selected to construct a dose-response plot to histamine aerosol. From this plot, the dose of histamine required to produce a $20 \%$ decrease in $\mathrm{FEV}_{1}$ was calculated and defined as the $20 \%$ provocative dose $\left(\mathrm{PD}_{20}\right)$. Five breaths were delivered to the patient from the dosimeter at each concentration tested.

Immediately after histamine-induced bronchoconstriction, the patient inhaled increasing concentrations of isoproterenol $(0.01,0.02$, $0.04,0.08,0.16$, and $0.32 \%$ ) if an inhalation of saline did not produce bronchodilation. From these values, maximum bronchodilation and the concentration of isoproterenol that gave $50 \%$ maximum bronchodilation $\left(\mathrm{ED}_{50}\right)$ was calculated.

The principles for antigen bronchoprovocation challenge with ragweed extract were similar to those described for histamine except that increases in concentration were separated by 10 -min intervals. Antigen concentration was increased until the $\mathrm{FEV}_{1}$ fell at least $20 \%$ and was maintained at this level for $10 \mathrm{~min}$. After antigen challenge, pulmonary functions were repeated at $0.5,1,2,3,4,5$, and $6 \mathrm{~h}$ to determine if an LAR occurred ( $>15 \%$ decrease in FEV, from baseline values).

Measurement of plasma histamine in relationship to antigen-provoked airway obstruction. To determine the effect of antigen inhalation on airway function and changes in plasma histamine, the protocol below was followed. On the day of antigen bronchoprovocation, an intravenous catheter was placed in the left antecubital fossa vein before beginning any inhalation. Approximately $10 \mathrm{~min}$ after the catheter was inserted, two plasma samples were obtained, which served as baseline sources for plasma histamine. When cumulative doses of inhaled antigen caused a $20 \%$ drop in $\mathrm{FEV}_{1}$ (determined 10 min after antigen delivery), another $10 \mathrm{ml}$ of blood was drawn with repeat samples 5,10 , and $15 \mathrm{~min}$ later. The blood was immediately anticoagulated with 50 $\mu \mathrm{l}$ of a $0.5 \mathrm{M}$ EDTA solution, placed in ice, and then centrifuged. The plasma was frozen $\left(-80^{\circ} \mathrm{C}\right)$ and later analyzed for histamine by a radioenzymatic assay as described previously (23). This assay uses histamine $N$-methyltransferase and $S$-adenosyl- $C$-[ $\left[{ }^{3} \mathrm{H}\right.$-methyl]methionine to convert histamine to $\left[{ }^{3} \mathrm{H}\right]$ tele-methylhistamine, which is then isolated from other radiolabeled material and finally quantitated by liquid scintillation. Standard curves were prepared for each experiment with histamine concentrations from 15 to $5,000 \mathrm{pg} / \mathrm{ml}$ (linear coefficient of variance equal to 0.99 ) and used to calculate the plasma histamine concentration. This method has greater sensitivity than the fluorometric technique to measure plasma histamine.

Serum IgE determinations. Serum IgE values were determined by a double-antibody, solid-phase, ELISA (Enzygnost IgE; CalbiochemBehring Corp., La Jolla, CA).

RVI6 inoculation. The technique for rhinovirus inoculation followed previously described methods $(24,25)$. Briefly, no patients had neutralizing antibody in their sera $(<1: 1)$ against a 20-25 tissue culture infective dose $50 \%\left(\mathrm{TCID}_{50}\right)$ challenge of RV16. Rhinoviral colds were induced in the 10 donors by instilling, on two successive days, $0.25 \mathrm{ml}$ of RV16 suspension into each nostril by pipette $(320-3,200$ $\mathrm{TCID}_{50}$ ) and then spraying approximately the same amount into each nostril with an atomizer (No. 286; DeVilbiss Co.) powered by a compressor (561 series; DeVilbiss Co.). The coarse spray coated the nasal cavity well (as visualized by a head lamp).

Colds were evaluated with a questionnaire that was completed by the participant hourly during waking hours (26). Symptoms evaluated included cough, nasal discharge, sneezing, stuffy nose, headache, mal- aises, chills, or fever. Symptoms were graded: $0=$ absent, $1=$ mild, 2 $=$ moderate, or $3=$ severe. Total symptom scores of $\geq 12$ defined a severe cold, 7-11 a moderate cold, and $<7$ a mild cold.

Laboratory confirmation of a viral infection. Virus shed by the inoculated subjects was assayed by titration of a nasal wash into diploid (WI-38) cell cultures. Nasal washes were taken by instilling $5 \mathrm{ml}$ of HBSS with $0.5 \%$ gelatin into each nostril, holding for $5 \mathrm{~s}$, and then expelling into a sterile petri dish. Nasal washes were inoculated into WI-38, primary rhesus monkey, and HEp-2 cell cultures, and post-experimental washings into WI-38 cells only $(24,25)$. Etiology was established by at least one identified isolate and/or by a fourfold or greater increase in neutralizing antibody in the convalescent serum specimens (24). Antibody titers were expressed as initial serum dilutions in which 1:1 = undiluted serum, 1:2 = one part serum and one part diluent, etc.

$P M N$ cAMP response. The isolated suspensions of intact PMNs were suspended in a $50 \mathrm{mM}$ Tris saline buffer with $8 \mathrm{mM}$ theophylline at a cell concentration of $1 \times 10^{7} \mathrm{PMN} / \mathrm{ml} ; 0.2-\mathrm{ml}$ aliquots of PMN were incubated $\left(37^{\circ} \mathrm{C}\right)$ with isoproterenol $(10 \mu \mathrm{M}$ for $2 \mathrm{~min})$, a time predetermined to give maximal stimulation of cAMP in the PMN. The reaction was terminated by boiling the cell suspension for $3 \mathrm{~min}$. cAMP was determined by a protein binding assay as described by Brown and colleagues (27). The percent increase in cyclic cAMP was calculated with the following equation:

$\left(\mathrm{CAMP}_{\mathrm{I}}-\mathrm{cAMP}_{\mathrm{B}}\right) / \mathrm{cAMP} \mathrm{B}_{\mathrm{B}} \times 100$,

where I equals isoproterenol and B equals baseline.

Statistical analysis. The data were analyzed in consultation with the University of Wisconsin, Madison, Biostatistics Department. A variety of statistical tests, including Spearman Rank Correlation Coefficient, McNemar's Test, Paired Wilcoxon Test, and an analysis of variance were used. Nonparametric tests of statistical significance were used because of the limited number of patients in the study and since the true underlying distribution of data may not have been normal. A $P$ value $<0.05$ was considered significant. The statistical tests used for individual analyses are indicated when levels of significance are expressed.

\section{Results}

Results of RV16 inoculation. 9 of the 10 patients inoculated with RV16 had this virus identified in nasal washes (Table I). Further, eight of the nine patients from whom convalescent sera were available had at least a fourfold rise in RV16-specific antibody. Patient 7 moved from Wisconsin and was unavailable for convalescent testing. Patient 10 was shedding a wild $\mathrm{RV}$ at the time of inoculation and continued to shed this virus throughout the experiment. Because he was infected with a $\mathrm{RV}$, his data were included in the study. Therefore, all 10 patients studied were considered to have a RV infection.

Effect of $R V$ on pulmonary functions and airway responsiveness. Spirometry values $\left(\mathrm{FEV}_{1}, \mathrm{FVC}, \mathrm{FEF}_{25-75 \%}\right)$ were similar at each of the three study periods: preinfection, acute infection, and postinfection, and were $\geqq 95 \%$ of the predicted representative values for each patient (Table II).

During the acute $\mathrm{RV}$ infection, airway reactivity to histamine was significantly $(P=0.019$, paired Wilcoxon Test) enhanced from baseline values (Fig. 2). The mean value for the histamine $\mathrm{PD}_{20}$ value has a large standard error which indicates the wide range in $\mathrm{PD}_{20}$ determinations to aerosol histamine, 8.8 to 300 cumulative breath units, in the allergic rhinitis patients studied. However, only one of the patients failed to have a fall in the histamine $\mathrm{PD}_{20}$ value during the acute rhinovirus respiratory infection (patient 2 ). Airway reactivity to ragweed antigen was also significantly enhanced over pre-in- 
Table I. Clinical Response to RV16 Inoculation

\begin{tabular}{ccrcc}
\hline Patient & $\begin{array}{c}\text { Highest } \\
\text { symptom score }\end{array}$ & $\begin{array}{c}\text { Highest virus } \\
\text { titer }\end{array}$ & $\begin{array}{c}\text { Highest } \\
\text { mucous index* }\end{array}$ & $\begin{array}{c}\text { Convalescent } \\
\text { titers }\end{array}$ \\
\hline & \multicolumn{5}{c}{$T C I D_{s 0} / m l$} \\
1 & 6 & 100,000 & 2 & \\
2 & 9 & 3,200 & 1 & $\geq 1: 45$ \\
3 & 5 & 3,200 & 0.5 & $1: 8$ \\
4 & 14 & 320,000 & 1.5 & $1: 32$ \\
5 & 13.5 & $1,000,000$ & 2 & $1: 45$ \\
6 & 6 & 320,000 & 1 & $1: 23$ \\
7 & 6 & $\geq 3,200,000$ & 3 & ND \\
8 & 12 & 3,200 & 1 & $1: 23$ \\
9 & 16 & 10,000 & 1 & $1: 64$ \\
$10^{\S}$ & 5 & 320 & 0.25 & $<1: 1$ \\
\hline
\end{tabular}

*, Amount of nasal mucus in the nasal wash: 0 , none; 1 , one third mucus; 2 , two-thirds mucus; 3 , all mucus.

‡, No data for leukocyte HR.

\$, This patient was shedding a wild RV (not RV16) at the time of inoculation. None of the subsequent isolates were inhibited by RV16 antisera, nor did the patient seroconvert. The wild $\mathrm{RV}$ apparently prevented inhibition by RV16, but the evidence is not unequivocal: the nasal wash suspensions were not incubated in antisera to this wild RV and then tested for breakthrough RV16.

fection values during the acute viral respiratory illness $(P$ $=0.014$, paired Wilcoxon Test). The relative change in acute airway responsiveness to histamine and ragweed antigen was similar during infection when compared with baseline values.

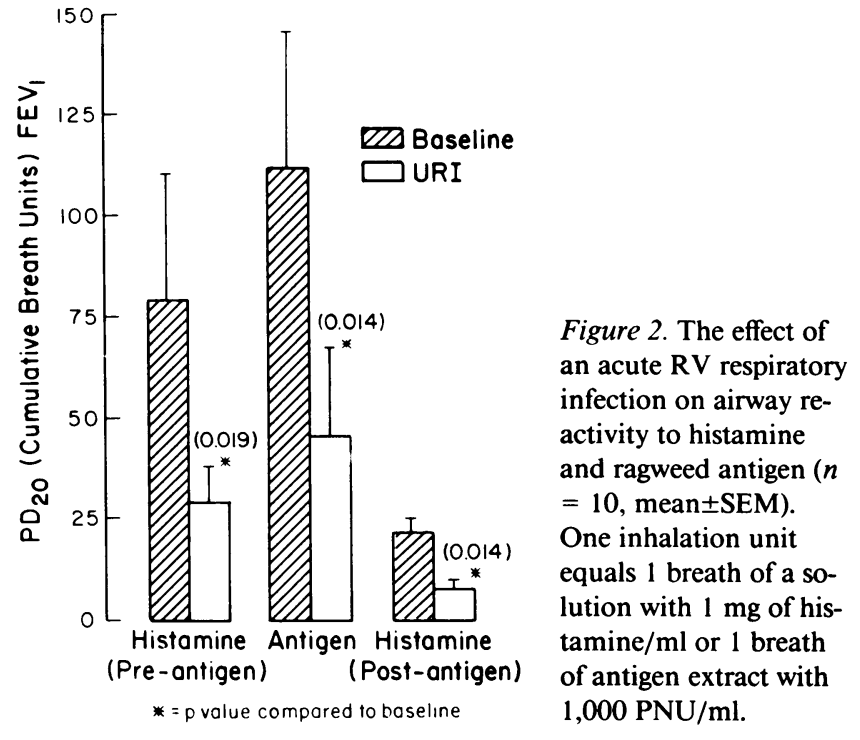

When airway reactivity to histamine was determined $24 \mathrm{~h}$ after ragweed antigen challenge, a significant $(P<0.036$, paired Wilcoxon Test) enhancement in airway reactivity was noted at both baseline and during the acute RV infection (Fig. 2). During the acute RV infection, airway reactivity to histamine, after ragweed antigen inhalation challenge, was also significantly enhanced when compared with its baseline counterpart $(P=0.014$, paired Wilcoxon Test). The relative enhancement of airway reactivity to histamine after antigen challenge

Table II. Individual Patient Responses at Each of the Three Study Periods: Baseline, Acute URI, and Recovery

\begin{tabular}{|c|c|c|c|c|c|c|c|c|c|c|c|c|c|c|}
\hline \multirow[b]{3}{*}{ Patient } & \multirow[b]{3}{*}{ Sex } & \multicolumn{5}{|c|}{ Baseline } & \multicolumn{4}{|c|}{ URI } & \multicolumn{4}{|c|}{ Recovery } \\
\hline & & \multirow[b]{2}{*}{ Age } & \multirow[b]{2}{*}{$\mathrm{FEV}_{1}(\mathrm{~L})$} & \multicolumn{3}{|c|}{$\mathrm{PD}_{20}$} & \multirow[b]{2}{*}{$\mathrm{FEV}_{1}$} & \multicolumn{3}{|c|}{$\mathrm{PD}_{20}$} & \multirow[b]{2}{*}{$\mathrm{FEV}_{1}$} & \multicolumn{3}{|c|}{$\mathrm{PD}_{20}$} \\
\hline & & & & Hist 1 & Antigen & Hist 2 & & Hist 1 & Antigen & Hist 2 & & Hist 1 & Antigen & Hist 2 \\
\hline & & $y r$ & $\%$ predict & & & & $\begin{array}{c}\text { liters/ } \\
\% \text { predict }\end{array}$ & & & & $\begin{array}{c}\text { liters/ } \\
\% \text { predict }\end{array}$ & & & \\
\hline 1 & $\mathbf{M}$ & 26 & $3.56(99)$ & 68.0 & 68.0 & 22.0 & $3.42(95)$ & 47.3 & 35.2 & 9.4 & $3.42(95)$ & 62.0 & 102.0 & 5.8 \\
\hline 2 & $\mathbf{M}$ & 25 & $4.07(100)$ & 10.2 & 15.5 & 2.3 & $3.91(96)$ & 24.0 & 33.0 & 7.2 & - & - & - & - \\
\hline 3 & $\mathrm{~F}$ & 24 & 2.69 (99) & 300.0 & 300.0 & 25.0 & $2.59(95)$ & 84.0 & 170.0 & 18.0 & - & - & - & - \\
\hline 4 & $\mathbf{M}$ & 32 & $4.03(98)$ & 85.0 & 92.5 & 25.0 & $4.11(100)$ & 30.0 & 48.0 & 14.0 & $4.09(100)$ & 40.0 & 85.0 & 12.0 \\
\hline 5 & $\mathbf{M}$ & 33 & $3.52(95)$ & 9.4 & 8.3 & 5.0 & $3.71(100)$ & 2.3 & 2.9 & 0.6 & $3.56(96)$ & 4.6 & 10.8 & 0.8 \\
\hline 6 & $\mathbf{M}$ & 40 & $4.30(101)$ & 16.0 & 210.0 & 6.8 & $4.24(106)$ & 9.0 & 10.8 & 6.0 & $4.72(117)$ & 12.0 & 4.2 & 6.5 \\
\hline 7 & $\mathbf{M}$ & 32 & $4.81(118)$ & 140.0 & 66.0 & 30.0 & $4.78(117)$ & 72.0 & 1.0 & 13.4 & $4.78(117)$ & 105.0 & 7.8 & 28.0 \\
\hline 8 & $\mathbf{M}$ & 44 & $3.39(97)$ & 20.0 & 100.0 & 19.0 & $3.41(98)$ & 5.5 & 58.0 & 3.1 & $3.46(99)$ & 7.2 & 120.0 & 3.8 \\
\hline 9 & $\mathbf{M}$ & 24 & $4.10(95)$ & 140.0 & 250.0 & 15.0 & $4.41(103)$ & 2.6 & 9.5 & 0.6 & - & - & - & - \\
\hline 10 & $\mathbf{F}$ & 26 & $3.65(99)$ & 8.8 & 11.8 & 12.5 & $3.63(98)$ & 3.2 & 6.5 & 4.8 & $3.55(96)$ & 5.8 & 34.0 & 0.4 \\
\hline \multicolumn{2}{|c|}{$(n=10)$} & $\begin{array}{l}30.6 \\
(2.1)\end{array}$ & $\begin{array}{c}100 \\
(2.1)\end{array}$ & $\begin{array}{c}79.7 \\
(29.4)\end{array}$ & $\begin{array}{l}112.2 \\
(33.1)\end{array}$ & $\begin{array}{l}16.3 \\
(3.0)\end{array}$ & $\begin{array}{c}100 \\
(2.1)\end{array}$ & $\begin{array}{c}28.0^{*} \\
(9.6)\end{array}$ & $\begin{array}{r}37.5^{\ddagger} \\
(16.0)\end{array}$ & $\begin{array}{r}7.7^{\ddagger} \\
(1.7)\end{array}$ & & & & \\
\hline \multicolumn{3}{|c|}{$\begin{array}{c}\text { ( } n=7 \text { patients } \\
\text { tested at all } \\
\text { three times) }\end{array}$} & $\begin{array}{c}101 \\
(2.9)\end{array}$ & $\begin{array}{c}49.6 \\
(18.9)\end{array}$ & $\begin{array}{c}79.5 \\
(25.6)\end{array}$ & $\begin{array}{l}17.2 \\
(3.6)\end{array}$ & $\begin{array}{c}102 \\
(2.8)\end{array}$ & $\begin{array}{c}24.2^{\S} \\
(10.2)\end{array}$ & $\begin{array}{r}23.2^{\S} \\
(8.9)\end{array}$ & $\begin{array}{r}7.3^{\S} \\
(1.9)\end{array}$ & $\begin{array}{c}103 \\
(3.7)\end{array}$ & $\begin{array}{l}33.8^{\| * *} \\
(14.4)\end{array}$ & $\begin{array}{c}52.0^{\pi} \\
(18.6)\end{array}$ & $\begin{array}{l}9.1^{* *} \\
(3.6)\end{array}$ \\
\hline
\end{tabular}

Hist 1 , the histamine response on day 1 of each of the study periods. Hist 2, the airway response to histamine $24 \mathrm{~h}$ after antigen challenge. Values are expressed as mean $( \pm \mathrm{SE})$. Statistical analysis for significance by paired Wilcoxon test. ${ }^{*}$ Baseline vs. URI, $P=0.019$. ${ }^{\ddagger}$ Baseline vs. URI, $P=0.014$. ${ }^{\S}$ Baseline vs. URI, $P=0.022$. "URI vs. recovery, $P=0.022$. "URI vs. recovery, $P=0.035$. "** Baseline vs. recovery, $P=0.022$. 
during the respiratory infection was similar to the changes in histamine reactivity measured before viral infection.

Seven of the patients were available for evaluation of airway reactivity 4 wk after virus infection (recovery). In these seven patients (Fig. 3), changes in the pattern of airway reactivity to histamine (preantigen) and ragweed antigen (baseline vs. URI) were similar to those described with all 10 patients (Fig. 2). However, 4 wk after the acute $R V$ infection, airway reactivity to histamine (preantigen) showed a return toward baseline value but was still significantly $(P=0.022$ paired Wilcoxon Test) different than preinfection determinants. The $\mathrm{PD}_{20}$ value for antigen at recovery was less than baseline, but differences were not significant. In contrast, airway reactivity to histamine postantigen challenge remained unchanged from values during the acute URI. The individual patient responses at each study period are listed in Table II.

Effect of $R V$ infection on the development of LARs. After bronchoprovocation with ragweed antigen, all patients were evaluated for the development of LARs, which were defined as a $15 \%$ drop in $\mathrm{FEV}_{1}$ within $6 \mathrm{~h}$ of antigen challenge (Fig. 4). At baseline (preinfection) evaluation, only 1 of the 10 subjects had an LAR. When the same evaluation was performed during acute RV infection, 8 of 10 subjects had LARs $(P=0.0085$, McNemar's Test). If the relationship between the development of an LAR was compared with indices of airway reactivity (Spearman rank correlation), no correlations were found between the LAR and $\mathrm{PD}_{20}$ values for histamine or antigen, or between changes in those values from baseline measurements. This indicated that the development of an LAR was independent of enhanced airway reactivity found during the cold. Furthermore, although there was a trend for a larger percent fall in $\mathrm{FEV}_{1}$ to inhaled antigen during the URI compared with baseline $(P=0.08$, Wilcoxon paired analysis; Table III), there was no significant positive correlation between the fall in $\mathrm{FEV}_{1}$ to antigen at baseline $(r=-0.541, P=0.11)$ or during the URI $(r$ $=-0.188, P=0.60$ ) with the development of LARs (analyzed by Spearman rank correlation coefficient). Our data thus indicate that the development of an LAR was also independent of

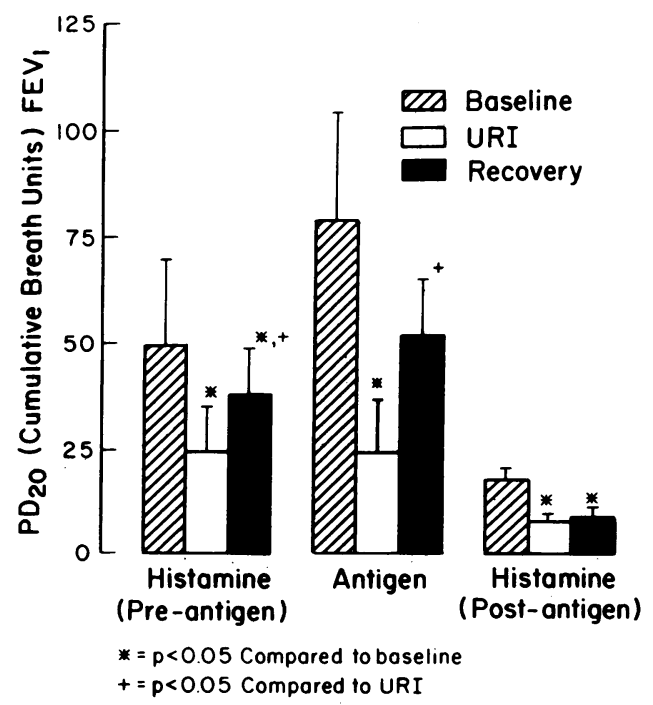

Figure 3. A comparison of the airway response to histamine and ragweed antigen at baseline, during an acute $\mathrm{RV}$ respiratory illness, and 4 wk later at recovery $(n=7$, mean \pm SEM $)$.

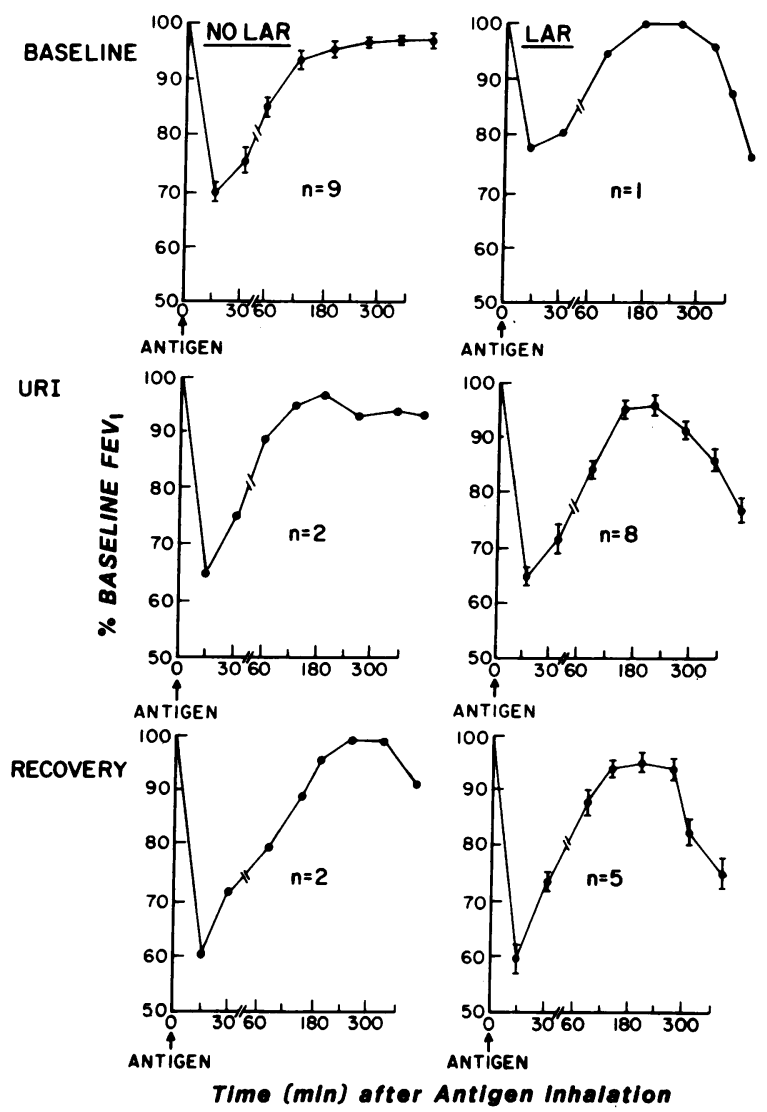

Figure 4. A comparison of the $\mathrm{FEV}_{1}$ response to inhaled ragweed in patients with and without LAR at baseline, acute URI, and recovery. Values are expressed as mean values or mean $\pm \mathrm{SE}$.

the intensity of the immediate response to antigen. Finally, during recovery, four of the seven continued to demonstrate LARs and one additional subject developed a LAR after allergen challenge.

Effect of antigen provocation on airway reactivity independent of $R V$ infections. Because antigen provocation caused enhanced airway reactivity to aerosol histamine, we were interested in the duration of this effect independent of $R V$ infection. In a subsequent series of experiments, seven of the allergic rhinitis subjects from this study were reevaluated. We found that the enhanced airway reactivity to histamine that follows antigen provocation lasts $<2 \mathrm{wk}$ in these allergic rhinitis patients (Table IV). Since the effects of RV on airway reactivity were evaluated $4 \mathrm{wk}$ after an antigen challenge, the initial antigen challenge at baseline should not have caused enhanced bronchial responsiveness during the acute $\mathrm{RV}$ infection.

Effect of $R V$ on basophil HR. Leukocyte HR to various concentrations of ragweed antigen $\mathrm{E}$, Con $\mathrm{A}$, and the calcium ionophore A23187 were evaluated at all three study periods. We found significant ( $P=0.027$, analysis of variance) enhancement of the ragweed antigen E-dependent basophil HR curves from cells studied during the acute RV infection (Fig. 5). In contrast, HR to Con A and calcium ionophore were not changed during the RV infection (data not shown). Furthermore, when similar evaluations were made 4 wk later at recovery, leukocyte HR to ragweed antigen had returned to baseline values in some, but not all, subjects. 
Table III. Individual Patient Response to Inhaled Ragweed Antigen at Baseline, URI, and Recovery

\begin{tabular}{|c|c|c|c|c|c|c|c|c|c|}
\hline \multirow[b]{3}{*}{ Patient } & \multicolumn{3}{|c|}{ Baseline } & \multicolumn{3}{|c|}{ URI } & \multicolumn{3}{|c|}{ Recovery } \\
\hline & & \multicolumn{2}{|c|}{$\%$ Fall FEV } & & \multicolumn{2}{|c|}{$\%$ Fall FEV } & & \multicolumn{2}{|c|}{ \% Fall FEV } \\
\hline & & Imm & Late & & Imm & Late & & Imm & Late \\
\hline & $B U$ & & & $B U$ & & & $B U$ & & \\
\hline 1 & 300.0 & 27.9 & 0.0 & 83.3 & 33.7 & 22.0 & 249.0 & 34.8 & 23.0 \\
\hline 2 & 33.0 & 34.0 & 2.3 & 53.8 & 35.8 & 18.2 & - & - & - \\
\hline 3 & 300.0 & 20.0 & 7.5 & 183.0 & 23.4 & 20.4 & - & - & - \\
\hline 4 & 300.0 & 36.2 & 4.7 & 83.2 & 30.9 & 19.0 & 163.0 & 47.9 & 12.0 \\
\hline 5 & 33.0 & 27.3 & 23.1 & 8.3 & 37.4 & 39.6 & 23.3 & 46.3 & 35.0 \\
\hline 6 & 300.0 & 37.0 & 2.7 & 33.3 & 43.4 & 15.0 & 8.3 & 47.1 & 17.3 \\
\hline 7 & 83.3 & 25.4 & 4.2 & 3.3 & 44.5 & 20.0 & 8.3 & 24.1 & 30.0 \\
\hline 8 & 300.0 & 32.9 & 0.0 & 300.0 & 39.3 & 5.7 & 300.0 & 39.2 & 7.5 \\
\hline 9 & 300.0 & 32.0 & 9.7 & 33.3 & 50.8 & 18.6 & - & - & - \\
\hline \multirow[t]{3}{*}{10} & 33.0 & $\underline{39.8}$ & 3.4 & 33.0 & $\underline{33.1}$ & 10.2 & 43.1 & $\underline{55.6}$ & $\underline{22.1}$ \\
\hline & $\overline{198.2}$ & $\overline{31.3}$ & $\overline{6.3}$ & $\overline{81.4^{*}}$ & $\overline{37.2}$ & $\overline{18.6^{\ddagger}}$ & $\overline{113.6}$ & $\overline{42.1}$ & $\overline{21.0}$ \\
\hline & \pm 41.8 & \pm 1.9 & \pm 2.1 & \pm 29.3 & \pm 2.5 & \pm 2.8 & \pm 46.5 & \pm 3.9 & \pm 3.6 \\
\hline
\end{tabular}

Data given include BU (cumulative breath units [in PNU] of antigen inhaled) and the percent fall in $\mathrm{FEV}_{1}$ at immediate (Imm) and late phase $\left(6 \mathrm{~h}\right.$ after antigen). Values are expressed as mean \pm SE. ${ }^{*}, P=0.011$, compared with baseline, Wilcoxon paired analysis. ${ }^{\ddagger}, P=0.006$, compared with baseline, Wilcoxon paired analysis.

These data were further evaluated to determine the effect respiratory infection had on various parameters of basophil HR. The antigen concentration required to achieve $50 \%$ maximal HR was similar at baseline $\left(5.5[ \pm 1.4] \times 10^{-4} \mu \mathrm{g} / \mathrm{ml}\right)$ and acute URI $\left(3.9[ \pm 1.4] \times 10^{-4} \mu \mathrm{g} / \mathrm{ml}\right)$. This suggests that there was no change in membrane-bound IgE antibody to ragweed during the infection. However, direct quantitation of basophil IgE was not made. Although serum levels of IgE antibody were found to be similar before $(264.3 \pm 93.6 \mathrm{IU} / \mathrm{ml})$, during $(254.0 \pm 82.4 \mathrm{IU} / \mathrm{ml})$, and $1 \mathrm{mo}$ after $\mathrm{RV}$ infection $(312.4 \pm 99.4$ $\mathrm{IU} / \mathrm{ml})($ values $=$ mean $\pm \mathrm{SEM})$, specific antibody to ragweed was not measured. These results are all indirect measures to assess cell bound antibody but, nonetheless, suggest no change in basophil IgE concentrations during infection.

Effect of $R \cdot V$ infection on plasma histamine concentrations after antigen challenge. Plasma levels of histamine obtained before antigen inhalation were higher during $\mathrm{RV}$ infection $(286 \pm 51 \mathrm{pg} / \mathrm{ml})$ than baseline values $(185 \pm 35 \mathrm{pg} / \mathrm{ml})$ but differences did not achieve significance $(P=0.103$, paired Wilcoxon Test). The plasma histamine levels were also determined after patients had inhaled a sufficient concentration of ragweed antigen to cause a $20 \%$ drop in $\mathrm{FEV}_{1}$. Plasma con-

Table IV. Effect of Ragweed Antigen Challenge on Histamine $P D_{20}$ Values and its Recovery

\begin{tabular}{lcc}
\hline & $\mathrm{PD}_{20}$ histamine values \\
\hline Baseline & $24 \mathrm{~h}$ postantigen & 2 wk postantigen \\
\hline $76.3 \pm 33.3$ & $27.1 \pm 10.6^{*}$ & $72.1 \pm 27.2$ \\
\hline
\end{tabular}

(Values are mean $\pm \mathrm{SE}, n=7$ ).

* $P=0.022$, compared with baseline and $2 \mathrm{wk}$ after antigen by Wilcoxon paired analysis. centrations of histamine increased after antigen exposure (peak values occurred 5-15 min after a 20\% reduction in $\mathrm{FEV}_{1}$ was achieved), both at baseline $(356 \pm 79 \mathrm{pg} / \mathrm{ml})$ and during acute infection $(350 \pm 48 \mathrm{pg} / \mathrm{ml})$, but were not different. However, limited time point determinations were made and the concentration of ragweed antigen required to decrease the $\mathrm{FEV}_{1}$ by $20 \%$ was less during acute infection (Table III).

Effect of $R V$ infection on beta adrenergic function. To determine the effect of RV infection on airway beta adrenergic function, dose-dependent bronchodilation to isoproterenol was measured after induction of bronchoconstriction with histamine. Airway beta adrenergic response was quantitated by the concentration of inhaled isoproterenol required to achieve complete reversal of airway obstruction and the concentration of isoproterenol necessary to cause $50 \%$ of maximum bronchodilation $\left(E_{50}\right)$. We found no change in airway response to beta adrenergic bronchodilation during the $\mathrm{RV}$ infection by either parameter (data not shown).

$P M N$ cAMP response to isoproterenol. The increase in PMN cAMP was determined to a $1.0 \times 10^{-5} \mathrm{M}$ concentration of isoproterenol. Because limited numbers of PMNs were available for study, only one concentration of isoproterenol $\left(1.0 \times 10^{-5} \mathrm{M}\right)$ was used to stimulate cAMP production. Before infection, the percent increase in PMN cAMP over baseline values $\left(4.5 \pm 0.9 \mathrm{pmol} / 10^{7} \mathrm{PMNs}\right)$ was $224 \pm 56 \%$. During the RV infection, concentrations of PMN cAMP (6.2 \pm 1.9 $\mathrm{pmol} / 10^{7} \mathrm{PMN}$ ) were similar to preinfection values. Although the percent increase in CAMP after stimulation with isoproterenol $\left(1.0 \times 10^{-5} \mathrm{M}\right)$ was less during RV16 infection than preinfection values, $158 \pm 56$ vs. $224 \pm 56 \%$, the differences were not significant:

\section{Discussion}

Our results demonstrate that $\mathrm{RV}$ infections can enhance airway responsiveness in allergic rhinitis patients and further, 


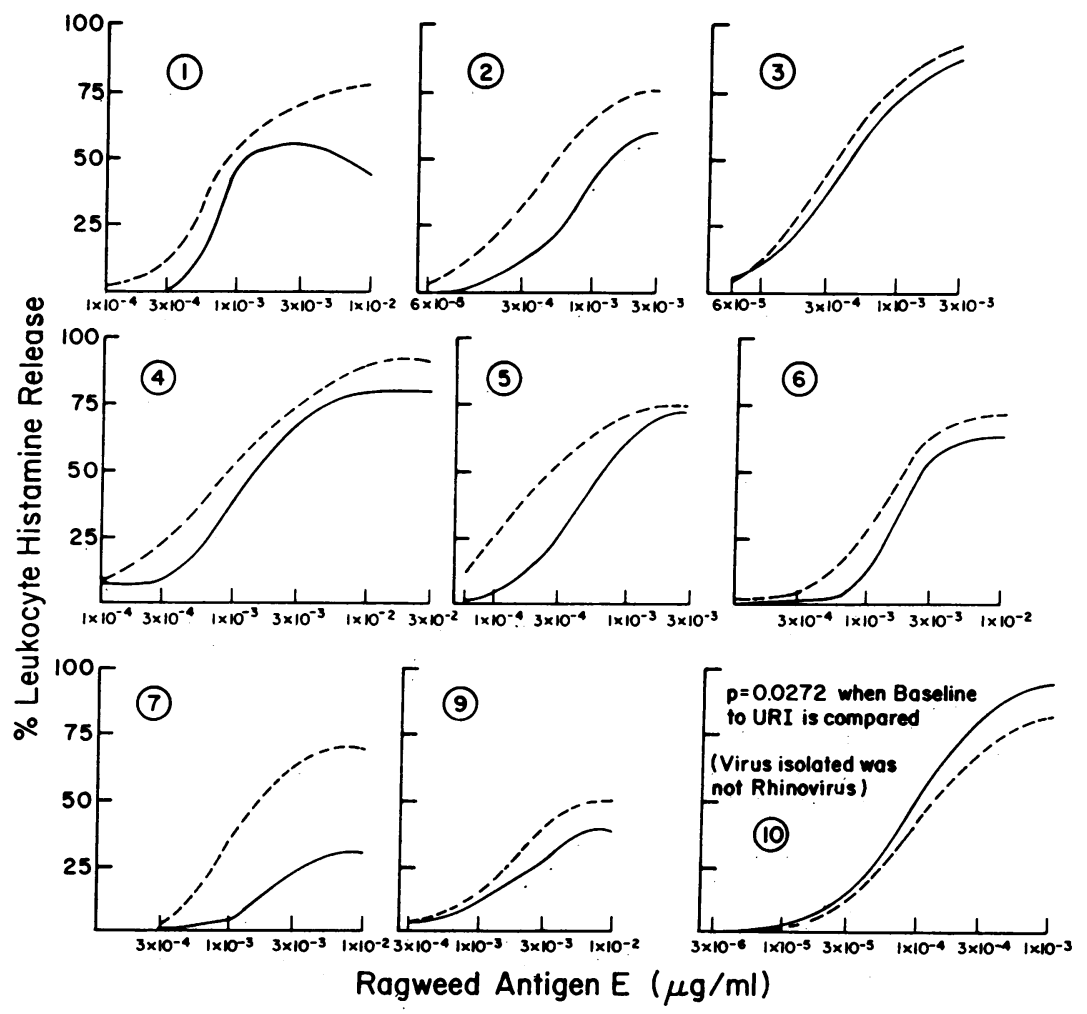

Figure 5. The effect of an acute RV infection on basophil HR to ragweed antigen E. Each frame represents one patient. —-, baseline; -.---, acute URI. that the viral infection alters the pattern of airway response to allergen challenge. These results confirm and extend previous observations using other model systems. Some $(6,28-30)$, but not all investigators $(31,32)$, have demonstrated that viral upper respiratory tract infections in both normal and asthmatic individuals can enhance airway responsiveness to challenge with such chemical irritants as histamine or methacholine. However, the magnitude of the change in responsiveness may be affected by a number of factors including the type and/or strain of virus, the severity of the infection, and the age of the patient. To our knowledge, our data are the first to demonstrate enhanced airway responsiveness to both allergen and histamine inhalation challenge after the experimental induction of a symptomatic viral upper respiratory tract infection in allergic rhinitis patients.

Before viral infection, allergen provocation resulted in enhanced reactivity to histamine $24 \mathrm{~h}$ later. This increase in airway responsiveness persisted for $<2 \mathrm{wk}$ in these patients with allergic rhinitis (Table IV). Of interest, however, is that allergen challenge resulted in significant increases although 9 of 10 patients developed isolated immediate responses only. Previous work has suggested that the induction of late-phase asthmatic reactions is necessary for the subsequent development of enhanced airway reactivity $(33,34)$. More recent work, however, has demonstrated that enhanced airway reactivity can be noted shortly after resolution of the immediate response (35). Our data indicate that the late response is not essential for the generation of enhanced airway reactivity and more importantly, changes in the threshold of airway responses to irritant stimuli can be observed in nonasthmatic patients. These findings could explain seasonal intolerances to exercise or irritant exposures in many allergic rhinitis patients.

During clinically symptomatic viral infections, however, the pattern of pulmonary response to allergen challenge differed significantly from that seen before the infection. LARs were observed in 8 of 10 patients during the infection compared with 1 of 10 before infection. The increased frequency of LARs during the viral infection could not be correlated with $\mathrm{PD}_{20}$ values for histamine or antigen during this observation period or with changes in these values from baseline measurements before infection. Enhanced airway reactivity or changes in airway reactivity by themselves, therefore, were not responsible for the change in the pattern of airway response to allergen provocation. Our results are in agreement with previous work using both allergen (36) and exercise (37) challenge in asthmatic patients in which baseline measurements of airway reactivity failed to correlate with the propensity to develop LARs. Although Crimi et al. (38) were able to determine a predictive index for LARs to house dust mite, this incorporated values for methacholine sensitivity, antigen-specific IgE in serum, and baseline $F E V_{1}$. When airway sensitivity to methacholine alone was used, no correlation was found with the development of LARs. Thus, although viral infection increased the threshold response to both histamine and allergen, these changes can not account for the increased frequency of LARs observed both during infection and the convalescent period. Furthermore, the intensity of the immediate response to antigen did not predict the development of the LAR during either the baseline period or during the URI. Together, these results indicate that viral URIs increase the propensity to develop LARs after allergen exposure by mechanisms that are independent of changes in airway reactivity or the magnitude of the immediate response to challenge.

To ascertain which factors were influential in altering the pattern of response to challenge, a number of potential contributing mechanisms were analyzed. Decreased beta adrener- 
gic control of airway tone has been proposed as one important factor in asthma pathogenesis (8). We have previously demonstrated that isolated leukocytes from asthmatic patients have diminished beta adrenergic responses (9); moreover, this response can be further diminished during viral respiratory infections in vivo (9) and after incubation with influenza virus (10) or rhinovirus (11) in vitro. In this series of experiments, however, we were unable to demonstrate a significant effect of $\mathrm{RV}$ infection on either the in vitro beta adrenergic response of isolated leukocytes or the in vivo airway response to isoproterenol. A number of factors may explain the differences between these results and those reported previously. First, in previous studies, in vitro beta adrenergic responsiveness was quantitated using a different model system (i.e., inhibition of granulocyte lysosomal enzyme release). Second, allergic rhinitis patients were evaluated in this report compared with asthmatic patients studied previously. Although a trend for diminished leukocyte beta adrenergic activity was noted, our results do not support a significant contribution of altered beta adrenergic responsiveness in PMNs or airway smooth muscle to the current observations.

To determine the effects viral infection had on mediator release, measurements of both plasma histamine and basophil HR were performed. Although plasma histamine levels obtained before antigen challenge were higher during the infection compared with baseline values, the differences were not significant. Moreover, increases in histamine levels after allergen challenge were no different during infection compared with baseline measurements. Although these results suggest that pulmonary mast cell histamine release may not be augmented after allergen exposure during viral URIs, and that rises in levels of this mediator cannot account for the changes in pulmonary response patterns noted, there are certain limitations to these observations. First, direct quantitation of pulmonary mast cell mediator release was not done and would be helpful in future studies to address this issue more specifically. Second, measurements of blood histamine levels after antigen challenge were limited in number and the dose of antigen required to decrease $\mathrm{FEV}_{1}$ during the acute infection was less than baseline. Third, histamine is but one mediator that can be released after mast cell activation (39) and further, its role in the development of the late-phase reaction in other target organs is felt to be minor $(40,41)$. Since the precise pathogenesis of LARs is still under study (42), it remains to be established which mediator(s) will be important to measure as either predictors or markers of the various types of patterns of pulmonary responses observed after allergen challenge (43).

In previous work, we have demonstrated that basophil histamine release is increased in asthma and that these increases correlate with measurements of airway reactivity in individual patients (44). After in vitro incubation with influenza A virus, leukocyte histamine release is also enhanced, an effect that may be due, at least in part, to IFN production $(15,16)$. Our present results extend our previous observations because they demonstrate that leukocyte $\mathrm{HR}$ is enhanced after in vivo infection with RV. Interestingly, the enhancement in leukocyte HR was noted only after exposure to ragweed antigen $E$. Direct measurement of cell-bound ragweed IgE antibody was not made; however, the total serum IgE antibody values were similar at baseline and URI. As serum IgE concentrations reflect basophil-bound antibody, this is an indirect suggestion that no change occurred in this parameter (45). Together, these results indicate that viral infection increases the intrinsic releasability of the basophilic leukocyte and that this process appears to be specific to antigen-triggered release events.

Although the mechanisms underlying these changes remain to be established, it is of interest that these alterations coincided temporally with significant changes in the pattern of airway response to allergen challenge. Basophils have recently been considered to be an important participant in the generation of nasal late-phase reactions (41). Although their role in LARs seems doubtful based on bronchoalveolar lavage studies in humans $(17,46,47)$ and histologic evaluations in animals models (48), our results suggest that basophil releasability and its potential relationship to the pattern of airway response to challenge should be more thoroughly evaluated. Furthermore, it is also possible that the function of other leukocytes, notably eosinophils, are enhanced by the rhinovirus and therefore more likely to contribute to the LAR.

$R V$ infections, both experimentally induced and arising from natural exposure, have been demonstrated to infect both the upper $(49,50)$ and lower $(32,51,52)$ respiratory tract. In the upper airway, no significant morphologic changes have been detected in the epithelial or subepithelial resident cell populations, but increases in PMN have been noted in the nasal epithelium (53). Comparable histopathologic evaluations have not been made in the lower respiratory tract but it is conceivable that, if similar findings were present, the polymorphonuclear cell infiltration may be a factor in contributing to the increased frequency of LARs noted in our patients during the time of their virus infection (54). However, it remains to be determined whether enhanced inflammation explains the persistence of the LAR during the convalescent phase of this study.

In summary, our data demonstrate that RV infections, due to a common cold virus that can infect humans, are capable of increasing the threshold response of airways to both antigen and histamine challenge. Of greater interest, however, is that LARs, felt to be an important model system for the study of chronic asthma, occur more frequently during RV infection and further, that the tendency to develop the LAR after challenge can persist for as long as 4 wk after infection. These observations are particularly relevant in that many previously asymptomatic asthmatic patients can relate the onset of their chronic asthma to an antecedent viral upper respiratory tract infection. Although the mechanisms underlying these events have not been entirely explained by our studies, our data have highlighted certain areas that will provide intriguing avenues for further investigation and possible explanations of the relationship between viral respiratory infections and airway hyperreactivity.

\section{Acknowledgments}

This work was supported by National Institutes of Health grants AI-10404, AI-15685, and K08-HL01147, and General Clinical Research Unit grant RR-03186.

\section{References}

1. McIntosh, K., E. F. Ellis, L. S. Hoffman, T. G. Lybass, J. J. Eller, and V. A. Fulginit. 1973. The association of viral and bacterial respiratory infections with exacerbations of wheezing in young asthmatic children. J. Pediatr. 82:578-590. 
2. Minor, T. E., E. C. Dick, A. N. DeMeo, J. J. Ouellette, M. Cohen, and C. E. Reed. 1974. Viruses as precipitants of asthmatic attacks in children. JAMA (J. Am. Med. Assoc.). 227:292-298.

3. Minor, T. E., E. C. Dick, J. W. Baker, J. J. Ouellette, M. Cohen, and C. E. Reed. 1976. Rhinovirus and influenza Type $A$ infections as precipitants of asthma. Am. Rev. Respir. Dis. 113:149-153.

4. Hudgel, D. W., C. Langston, Jr., J. C. Selner, and K. McIntosh. 1979. Viral and bacterial infections in adults with chronic asthma. Am. Rev. Respir. Dis. 120:393-397.

5. Busse, W. W. 1985. The precipitation of asthma by upper respiratory infections. Chest. 87:445-475.

6. Empey, D. W., L. A. Laitinen, L. Jacobs, W. M. Gold, and J. A. Nadel. 1976. Mechanisms of bronchial hyperreactivity in normal subjects after upper respiratory tract infection. Am. Rev. Respir. Dis. 113:131-139.

7. Saban, R., E. C. Dick, R. I. Fishleder, and C. K. Buckner. 1987. Enhancement by parainfluenza 3 infection of contractile responses to substance $\mathbf{P}$ and capsaicin in airway smooth muscle from the guinea pig. Am. Rev. Respir. Dis. 136:586-591.

8. Szentivanyi, A. 1968. The beta-adrenergic theory of the atopic abnormality in asthma. J. Allergy. 42:203-223.

9. Busse, W. W. 1977. Decreased granulocyte response to isoproterenol in asthma during upper respiratory infections. Am. Rev. Respir. Dis. 115:783-791.

10. Busse, W. W., W. Cooper, D. M. Warshauer, E. C. Dick, I. H. L. Wallow, and R. Albrecht. 1979. Impairment of isoproterenol, $\mathrm{H} 2$ histamine, and prostaglandin $\mathrm{E}_{1}$ response of human granulocytes after incubation in vitro with live influenza vaccines. Am. Rev. Respir. Dis. 119:561-569.

11. Busse, W. W., C. L. Anderson, E. C. Dick, and D. Warshauer. 1980. Reduced granulocyte response to isoproterenol, histamine, and prostaglandin $\mathrm{E}_{1}$ after in vitro incubation with rhinovirus 16. Am. Rev. Respir. Dis. 122:641-646.

12. Welliver, R. C., D. T. Wong, M. Sun, E. Middleton, Jr., R. S. Vaughan, and P. L. Ogra. 1981. The development of respiratory syncytial virus-specific IgE and the release of histamine in nasopharyngeal secretions after infection. N. Engl. J. Med. 305:841-846.

13. Welliver, R. C., D. T. Wong, E. Middleton, Jr., M. Sun, N. McCarthy, and P. L. Ogra. 1982. Role of parainfluenza virus-specific IgE in pathogenesis of croup and wheezing subsequent to infection. $J$. Pediatr. 101:889-896.

14. Welliver, R. L., M. Sun, D. Rinaldo, and P. L. Ogra. 1986. Predictive value of respiratory syncytial virus-specific IgE responses for recurrent wheezing following bronchiolitis. J. Pediatr. 109:776-880.

15. Busse, W. W., C. A. Swenson, E. C. Borden, M. W. Treuhaft, and E. C. Dick. 1983. Effect of influenza A virus on leukocyte histamine release. J. Allergy Clin. Immunol. 71:382-388.

16. Ida, S., J. J. Hooks, R. P. Siraganian, and A. L. Notkins. 1977. Enhancement of IgE-mediated histamine release from human basophils by viruses. Role of interferon. J. Exp. Med. 145:892-896.

17. Metzger, W. J., G. W. Hunninghake, and H. B. Richerson. 1985. Late asthmatic responses: inquiry into mechanisms and signifcance. Clin. Rev. Allergy 3:145-165.

18. Rosenthal, R. R. 1983. Differences in response between hay fever and asthmatic patients. In Provocative Challenge Procedures: Bronchial, Oral, Nasal, and Exercise. Vol. I. L. S. Spector, editor. CRC Press, Inc., Boca Raton, FL. 113-119.

19. Böyum, A. 1968. Isolation of mononuclear cells and granulocytes from human blood. Scand. J. Clin. Lab. Invest. 21 (Suppl. 97):77-89.

20. Siraganian, R. P. 1974. An automated continuous flow system for the extraction and fluorometric analysis of histamine. Anal. Biochem. 57:383-394.

21. Siraganian, R. P. 1980. Histamine release and assay method for study of human allergy. In Manual of Clinical Immunology. N. R. Rose and H. Friedman, editors. American Society for Microbiology, Washington, DC. 808-821.

22. Chai, H., R. Farr, and L. A. Froehlich. 1975. Standardization of bronchial inhalation challenge procedures. J. Allergy Clin. Immunol. $56: 323-327$

23. Bowsher, R. R., K. M. Verburg, and D. P. Henry. 1983. Rat histamine N-methyltransferase. Quantitation, tissue distribution, purification, and immunologic properties. J. Biol. Chem. 258:1221512220.

24. D'Alessio, D. J., J. A. Peterson, and E. C. Dick. 1976. Transmission of experimental rhinovirus colds in volunteer married couples. J. Infect. Dis. 133:28-36.

25. D'Alessio, D. J., C. K. Meschievitz, S. B. Schultz, and E. C. Dick. 1984. A model for obtaining predictable natural transmission of rhinoviruses in human volunteers. J. Infect. Dis. 150:195-201.

26. Jackson, G. G., H. F. Dowling, I. G. Spresman, and A. V. Boand. 1958. Transmission of the common cold to volunteers under controlled conditions. Arch. Intern. Med. 101:267-273.

27. Brown, B. L., J. D. M. Albano, R. P. Ekins, A. H. Sgerzi, and W. Tampion. 1971. A simple and sensitive saturation assay for the measurement of adenosine 3':5'-cyclic monophosphate. Biochemistry. 121:561-562.

28. Bush, R. K., W. Busse, D. Flaherty, D. Warshauer, E. C. Dick, and C. E. Reed. 1978. Effects of experimental rhinovirus 16 infection on airways and leukocyte function in normal subjects. J. Allergy Clin. Immunol. 61:80-87.

29. Hall, W. J., C. B. Hall, and D. M. Speers. 1978. Respiratory syncytial virus infection in adults. Ann. Intern. Med. 88:203-205.

30. Halperin, S. A., P. A. Eggleston, P. Beasley, P. Suratt, J. O. Hendley, D. H. M. Groschel, and J. M. Gwaltney. 1985. Exacerbations of asthma in adults during experimental rhinovirus infection. Am. Rev. Respir. Dis. 132:976-980.

31. Jenkins, C. R., and A. B. Breslin. 1984. Upper respiratory tract infections and airway reactivity in normal and asthmatic subjects. $\mathrm{Am}$. Rev. Respir. Dis. 130:879-883.

32. Halperin, S. A., P. A. Eggleston, J. O. Hendley, P. M. Suratt, D. H. M. Groschel, and J. M. Gwaltney. 1983. Pathogenesis of lower respiratory tract symptoms in experimental rhinovirus infection. $\mathbf{A m}$. Rev. Respir. Dis. 128:806-810.

33. Cockcroft, D. W., R. E. Ruffin, J. Dolovich, and F. E. Hargreave. 1977. Allergen-induced increase in nonallergic bronchial reactivity. Clin. Allergy. 7:503-513.

34. Cartier, A., N. C. Thomson, P. A. Frith, R. Roberts, and F. E. Hargreave. 1982. Allergen-induced increase in bronchial responsiveness to histamine: relationship to the late asthmatic response and change in airway caliber. J. Allergy Clin. Immunol. 70:170-172.

35. Thorpe, J. E., D. Steinberg, I. L. Bernstein, and C. G. Murlas. 1987. Bronchial reactivity increases soon after the immediate response in dual-responding asthmatic subjects. Chest. 91:21-25.

36. Robertson, D. G., A. T. Kerigan, F. E. Hargreave, R. Chalmers, and J. Dolovich. 1974. Late asthmatic responses induced by ragweed pollen allergen. J. Allergy Clin. Immunol. 54:244-254.

37. Iikura, Y., H. Inui, T. Nagakura, and T. K. Lee. 1985. Factors predisposing to exercise-induced late asthmatic responses. J. Allergy Clin. Immunol. 75:285-289.

38. Crimi, E., V. Brusasco, E. Losurdo, and P. Crimi. 1986. Predictive accuracy of late asthmatic reaction to Dermatophogoides pleronyssinus. J. Allergy Clin. Immunol. 78:908-913.

39. Wasserman, S. I. 1983. Mediators of immediate hypersensitivity. J. Allergy Clin. Immunol. 72:101-114.

40. Lemanske, R. F., L. Barr, D. A. Guthman, and M. A. Kaliner. 1983. The biologic activity of mast cell granules. V. The effects of antihistamine treatment on rat cutaneous early- and late-phase reactions. J. Allergy Clin. Immunol. 71:94-99.

41. Naclerio, R. M., D. Proud, A. Togias, N. F. Adkinson, D. A. Meyers, A. Kagey-Sobotka, M. Plautt, P. S. Norman, and L. M. Lichtenstein. 1985. Inflammatory mediators in late antigen-induced rhinitis. N. Engl. J. Med. 313:65-70.

42. O'Byrne, P. M., J. Dolovich, and F. E. Hargreave. 1987. Late asthmatic responses. Am. Rev. Respir. Dis. 136:740-751.

43. Pepys, J. 1977. Clinical and therapeutic significance of patterns 
of allergic reactions of the lungs to extrinsic agents. Am. Rev. Respir. Dis. 116:573-588.

44. Gaddy, J. N., and W. W. Busse. 1986. Enhanced IgE-dependent basophil histamine release and airway reactivity in asthma. Am. Rev. Respir. Dis. 134:969-974.

45. Malveaux, F. J., M. C. Conroy, N. F. Adkinson, Jr., and L. M. Lichtenstein. 1978. IgE receptors on human basophils. Relationship to serum IgE concentrations. J. Clin. Invest. 78:176-181.

46. DeMonchy, J. G. R., H. F. Kauffman, P. Venge, G. H. Koeter, H. M. Jansen, H. J. Sluiter, and K. deVries. 1985. Bronchoalveolar eosinophilia during allergen-induced late asthmatic reactions. $\mathrm{Am}$. Rev. Respir. Dis. 131:373-376.

47. Gonzalez, M. C., P. Diaz, F. R. Galleguillos, P. Ancic, O. Cromwell, and A. B. Kay. 1987. Allergen-induced recruitment of bronchoalveolar helper (OKT4) and suppressor (OKT8) T-cells in asthma. Relative increases in OKT8 cells in single early responders compared with those in late-phase responders. Am. Rev. Respir. Dis. 136:600-604.

48. Behrens, B. L., R. A. Clark, D. M. Presley, J. P. Graves, D. C. Feldsien, and G. L. Larsen. 1987. Comparison of the histopathology of early and late cutaneous and asthmatic responses in rabbits after a single antigen challenge. Lab. Invest. 56:101-113.
49. Winther, B., J. M. Gwaltney, Jr., N. Mygind, R. B. Turner, and J. O. Hendley. 1986. Sites of rhinovirus recovery after point inoculation of the upper airway. JAMA (J. Am. Med. Assoc.). 256:1763-1767.

50. Eggleston, P. A., J. O. Hendley, and J. M. Gwaltney, Jr. 1984 Mediators of immediate hypersensitivity in nasal secretions during natural colds and rhinovirus infection. Acta. Otolaryngol. Suppl. 413:25-35.

51. Krilov, L., L. Pierik, E. Keller, K. Mahan, D. Watson, M. Hirsch, V. Hamparian, and K. McIntosh. 1986. The association of rhinoviruses with lower respiratory tract disease in hospitalized patients. J. Med. Virol. 19:345-352.

52. Las Heras, J., and V. L. Swanson. 1983. Sudden death of an infant with rhinovirus infection complicating bronchial asthma: case report. Pediatr. Pathol. 1:319-323.

53. Winther, B., B. Farr, R. B. Turner, J. O. Hendley, J. M. Gwaltney, Jr., and N. Mygind. 1984. Histopathologic examination and enumeration of polymorphonuclear leukocytes in the nasal mucosa during experimental rhinovirus colds. Acta. Otolaryngol. Suppl. 413:19-24.

54. Murphy, K. R., M. C. Wilson, C. G. Irvin, L. S. Glezen, W. R. Marsh, C. Haslett, P. M. Henson, and G. L. Larsen. 1986. The requirement for polymorphonuclear leukocytes in the late asthmatic response and heightened airways reactivity in an animal model. Am. Rev. Respir. Dis. 134:62-68. 